\title{
Production of Nanofibres using Rotary Jet Spinning Method for Tissue Engineering
}

\author{
L. Nagarajan ${ }^{1}$, N. Gayathri ${ }^{2}$ \\ ${ }^{1}$ Associate Professor, Department of Textile Technology, Jaya Engineering College, Chennai - 602024 \\ ${ }^{2}$ M.Tech - II Year, Department of Textile Technology, Jaya Engineering College, Chennai - 602024
}

\begin{abstract}
Textile industry is a vast field in which the branch medical textile is growing one. The base for tissue engineering/medical textile is a textile material which acts as a backbone of Medical field. Various method of producing nanofibers for tissue engineering is a developing field of textiles, in which so many researches are going on. There is a great scope in this field where new inventions are being welcomed. Tissue Engineering is the reliable field which involves the principles of engineering, combination of cells and other factors, which helps in tissue repair and regeneration. To overcome the drawbacks with donor organs, tissue engineering was developed. Tissues are the group of cells with similar structure working together for specific function. There are four main tissues in the body. In case of any injury to the human tissue, to replace and repair the host one, tissue engineering is used. Nanofibers are the fibers with diameter less than 100nm. Nanofibers are produced by various techniques such as Electrospinning, Self-assembly, Rotary Jet spinning (RJS) method etc, in which RJS method is a developing one, which gives very high output than any other method. Tissue engineering with nanofibrous structure provides high surface area, adequate pore size, porosity, and biocompatibility. Nanofibrous structure can mimic the host architecture and functions. It also provides good mechanical properties and assists in cell adhesion, growth and proliferation. Some polymers produced as nanofibers are also biodegradable which mimic the activities of host and also helps to prevent further surgeries to remove the artificial one. They degrade by its own as the new tissue starts to grow. Thus the nanofibrous structure is suitable for biomedical applications and tissue engineering such as Skin, Cartilage etc., This article explains about tissue engineering, necessity for tissue engineering, how it is done, nanofibers and its properties and the different types of production methods of nanofibers.
\end{abstract}

Keywords: Tissue Engineering, Nanofibers, Biocompatibility, Electrospinning, Rotary Jet Spinning, Proliferation

\section{Introduction}

Textile Technology is an up growing field especially in the area Medicine. So many researches are being done in Medical field using textile materials as substrates. Among that, one of the successful methods is Tissue Engineering. It is the interdisciplinary field which involves the principles of engineering materials and methodologies, life sciences for tissue repair and regeneration. It involves the separation of cells from patients and seeding it onto 3D biodegradable scaffolds which helps in cell adhesion, growth and proliferation. These scaffolds gradually degrade by time as the new tissue starts to grow. And as biodegradable nanofibers are used as scaffolds then it eliminates the surgical removal of guest material. Hence the applications of nanofibers as scaffolds play a vital role in tissue engineering. These nanofibers are produced from polymers by various techniques such as Electrospinning, Phase separation etc., in which Rotary Jet spinning method is a growing one, which is very effective method when compared to other methods.

\section{Tissue Engineering}

Tissue Engineering is the study/field, which involves the cells, growth of new connective tissues or organs, engineering methods and materials, to repair and regenerate diseased/injured organs/body parts.

\section{Importance Of Tissue Engineering}

Since there is a great demand in supply of donor organs, tissue engineering helps a lot for the replacement of injured parts and to mimic the activities of host one.

As allograft, autograft methodologies require number of surgeries and for other non-biodegradable materials it requires secondary surgery for removal, to overcome all these drawbacks tissue engineering method was developed and it is the best one which eliminates the repetition of surgeries.

As the surgical reconstruction, drug delivery, medical devices are not successful always; tissue engineering is the best method which paves way for success. It eliminates the risk of organ rejection as it is made up of patient "s own cells. It eliminates the threat of disease and any risk. It helps people to save their lives and used in skin, bone, organ replacements etc.,

\section{Tissue And Its Types}

Tissues are groups of cells with a similar structure working together for specific function. Organs are formed by the functional grouping together of multiple tissues.There are four main tissues in the body - epithelium, muscle, connective tissue and nervous tissue.

\section{Epithelium}

Epithelium is made up of epithelial cells. These cells can be flat, cuboidal, or columnar. They are joined together very tightly tomakea continuous sheet. Thus epithelium forms as an excellent protective layer for the body in the form of skin. It acts as protective barrier and protects the body from radiation, bacteria, etc.,

How Nanofibers Are Suitable For Epithelium Tissue

1) Diameter of nanofibers can be matched with human skin - for example, dermis has the diameter approximately of $50 \mathrm{~nm}$, and it is possible to produce the nanofibers with the same range of skin"s diameter. 


\section{International Journal of Science and Research (IJSR) \\ ISSN (Online): 2319-7064}

Index Copernicus Value (2013): 6.14 | Impact Factor (2014): 5.611

2) Adequate porosity and pore size - It is required to maintain moisture, to assist in drug delivery, to exhaust serum, to prevent any other matters like bacteria penetrating inside

3) Drug delivery - It helps to deliver drug into the skin and assist in healing process

4) It also provides high surface area

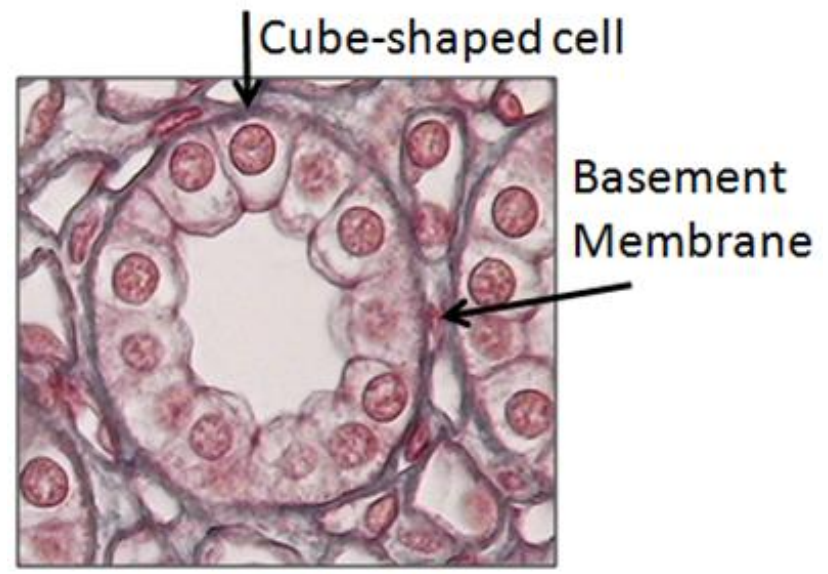

Simple Cuboidal

Epithelial Tissue

Figure 1: Epithelial Tissue

\section{Connective Tissue}

As its name suggests, connective tissue makes up a connective web inside our body. Holding our body parts together and providing support are the main jobs of this tissue. Connective tissue fills in the spaces inside our body with a matrix made of fibres within a liquid, solid, or jellylike substance. It protects our organs, stores nutrients.

\section{How Nanofibers Are Suitable For Connective Tissue}

1) Nanofiber scaffolds are suitable for cell culture, growth, proliferation and new tissue formation.

2) And it helps to mimic the activities of connective tissue, such as providing support and protection.

3) Artificial tissue with nanofibers underlies strongly and slowly degrades when the new tissue starts to grow.

4) It helps in cell adhesion, growth and proliferation.

5) Promote tissue regeneration and drug delivery

\section{Special Connective Tissues}

\section{Cartilage}

It is a flexible connective tissue, including joints between bones, rib cage, ear, and nose. It is not hard and rigid as much as bone, but it is stiffer and less flexible than muscle.

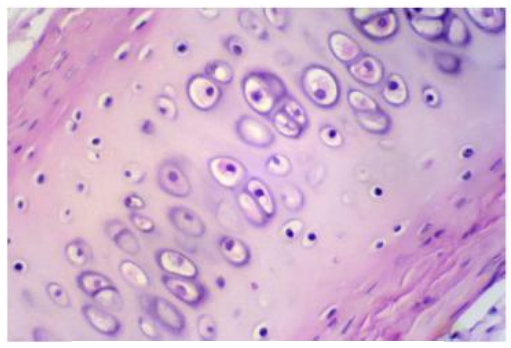

Figure 2: Cartilage Tissue

\section{How Nanofibers Are Suitable For Cartilage}

1) Normally articular cartilage has poor regenerative properties. Once injured, self-healing is much more difficult. But tissue engineering with nanofibers have great potential in cartilage repair, which aims to repair, regenerate and improve diseased or injured cartilage function.

2) "Repair" denotes the restoration of normal function; "Regeneration" not only denotes the restoration of normal function but also results in the formation of new tissue.

3) To attain the same/similar morphology with great mechanical properties is possible with nanofibers in tissue engineering.

\section{Bone}

It provides strength for body, and helps for movement. It stores calcium and contains blood forming vessels.

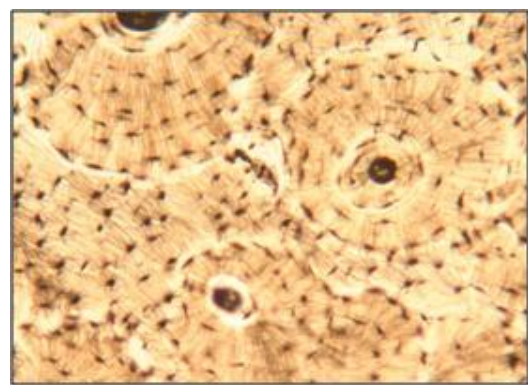

Figure 3: Bone Tissue

\section{How Nanofibers Are Suitable For Bone}

1) Basically bone has low regenerative property. But nanofibrous scaffolds can mimic the architecture of host tissue at nanometer scale. It assists in cell adhesion, proliferation and differentiation.

2) Nanofibrous scaffolds with pore size range 100-350 microns and porosity greater than $90 \%$ can be achieved which helps in better cell growth and also assists in bone regeneration.

\section{Blood}

Blood is a bodily fluid which delivers nutrients and oxygen to the cells and transports metabolic wastes away from the same cells. It helps in immunological functions, including circulation of white blood cells.

\section{How Nanofibers Are Suitable For Blood}

1) Earlier the development of vascular grafts had problem with inflowing blood and adjacent tissues. But the grafts made up of nanofibers can interact better with cells and cause blood vessel formation.

2) Nanofibrous structure can mimic the natural ECM, provide good mechanical properties in artery, and the morphology helps in better cell adhesion and proliferation.

3) Aligned fibers not only give proper morphology but also provides good mechanical strength to sustain high pressure of human circulatory system. 


\section{International Journal of Science and Research (IJSR) \\ ISSN (Online): 2319-7064}

Index Copernicus Value (2013): 6.14 | Impact Factor (2014): 5.611

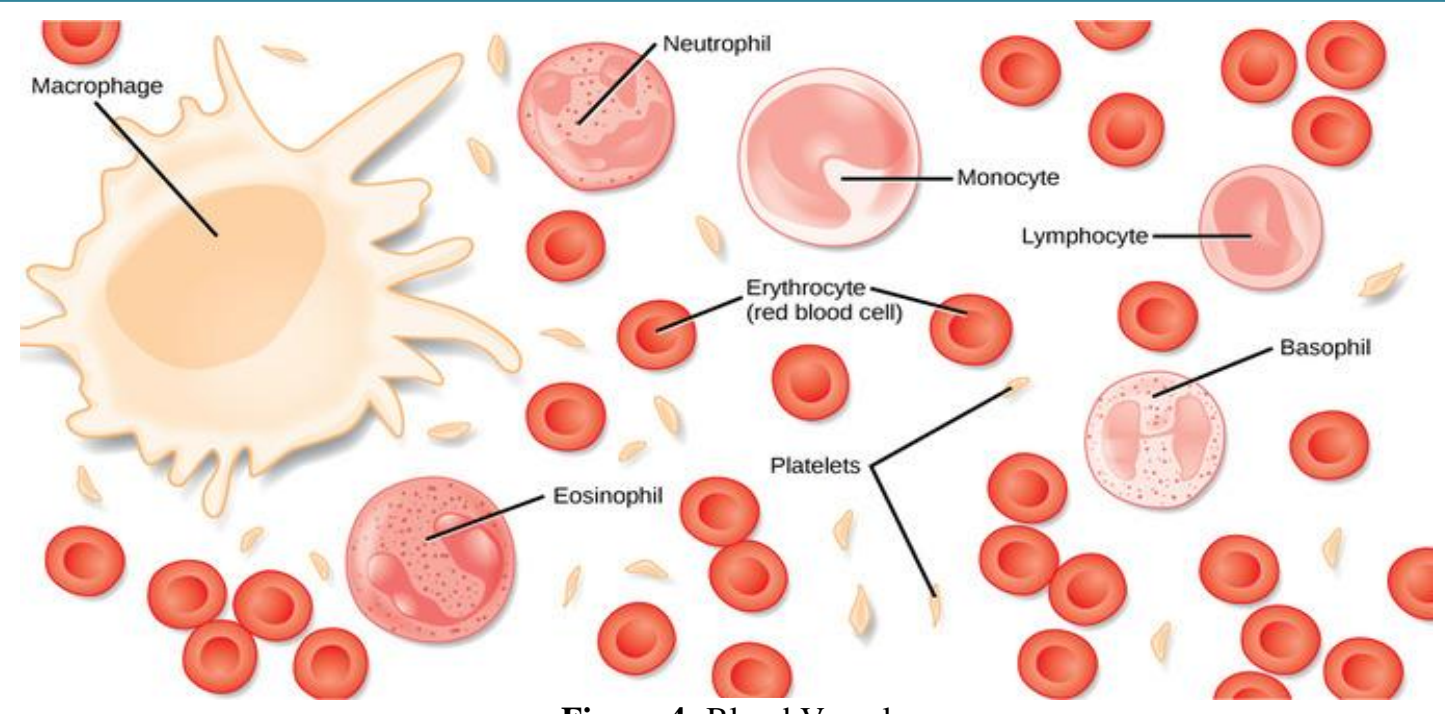

Figure 4: Blood Vessel

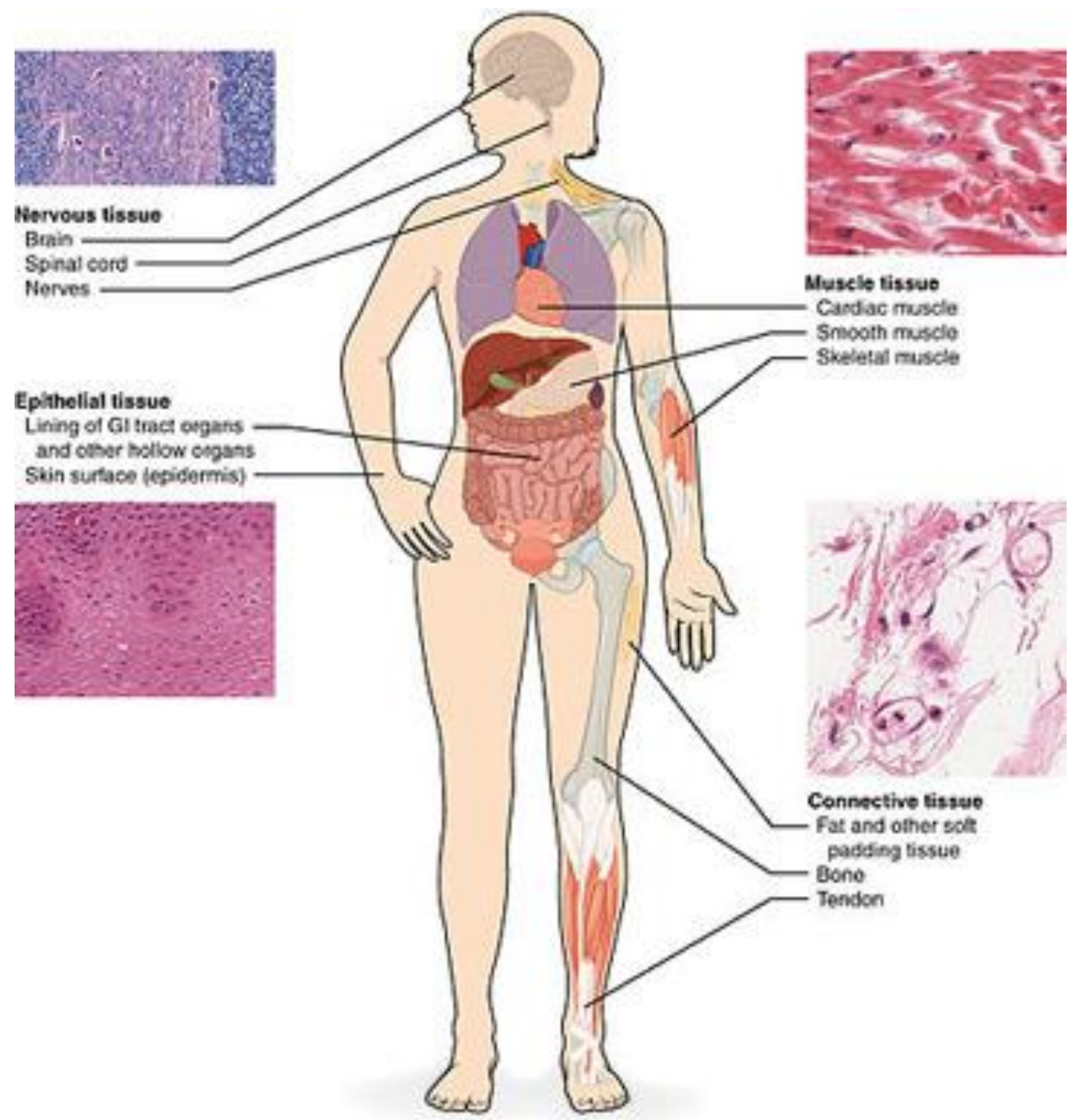

Figure 5: Different types of tissue

Nervous Tissue

Nervous tissue is found within the nervous system and is made up of unique specialized cells. The nervous system transmits signals from nerves to the spinal cord and brain. It regulates and controls the bodily functions and activity. Its main function is to conduct impulses to various organs in the body through neurons.

\section{Volume 5 Issue 3, March 2016}




\section{International Journal of Science and Research (IJSR) \\ ISSN (Online): 2319-7064 \\ Index Copernicus Value (2013): 6.14 | Impact Factor (2014): 5.611}

How Nanofibers Are Suitable For Nervous

1) Neural injuries cause irreversible loss of functioning.

2) Hence nanofibrous structure aims to repair and regenerate injured nerves.

3) Nanofibrous scaffolds made with normal engineered cells and ECM equivalents along with synthetic tools helps to mimic host activities and for drug delivery.

4) This provides high surface area.

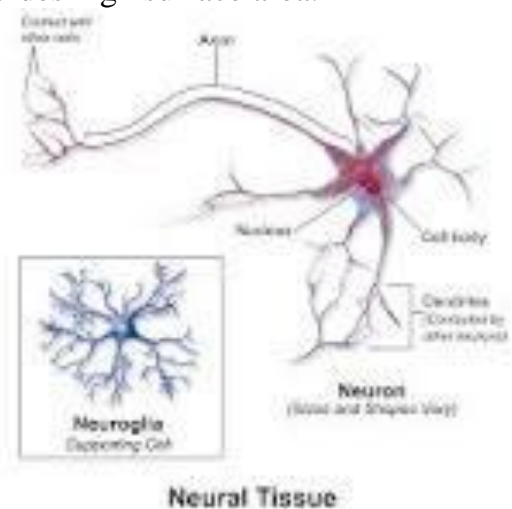

Figure 6: Neural Tissue
It is a soft tissue that composes muscle, which is responsible for body movement and responsible for mechanical digestion. It moves blood, food, and waste through organs.
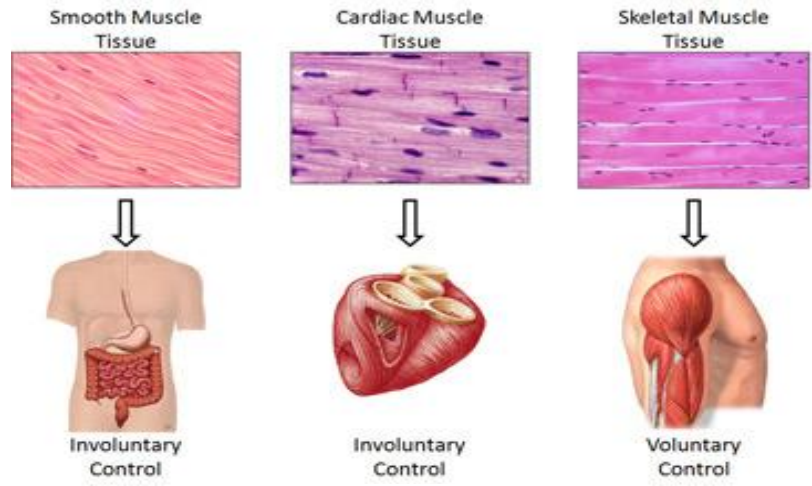

Figure 7: Muscle Tissue

How Tissue Engineering is Done

\section{Muscle Tissue}

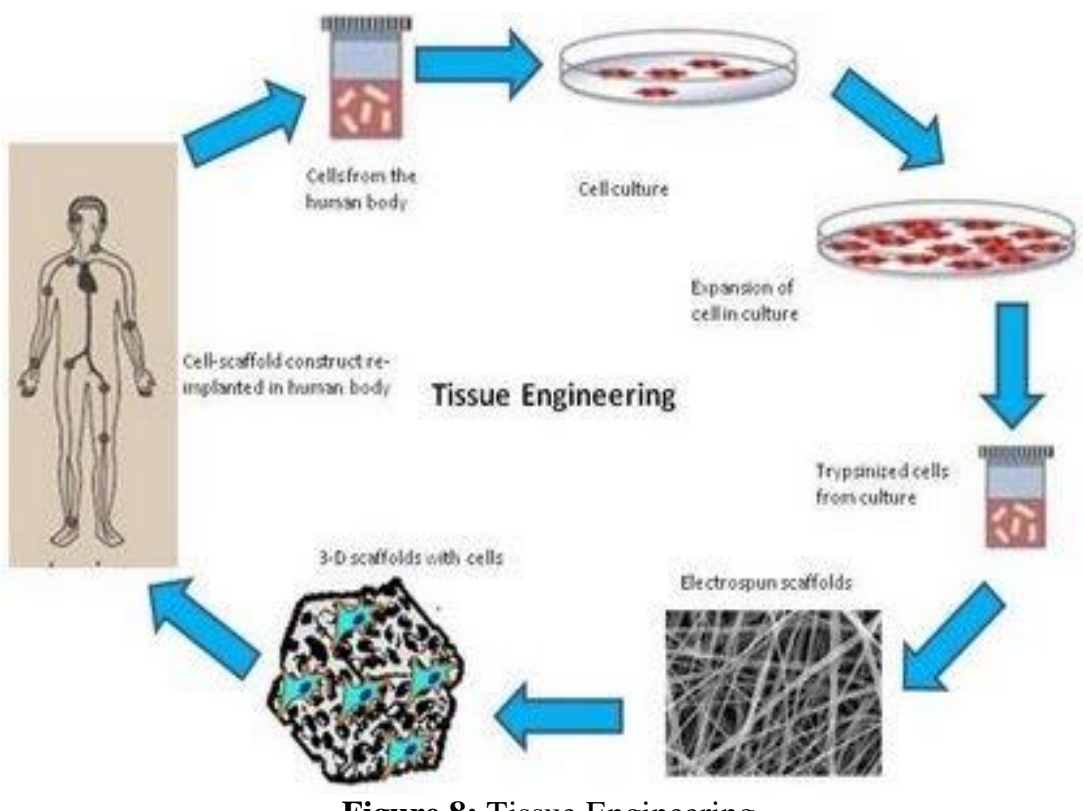

Figure 8: Tissue Engineering

The concept of Tissue Engineering is to culture cells in vitro on a 3D nanofibrous scaffold and implant it inside the body of an individual where it grows and perform repair action.

The steps involved in Tissue Engineering are as below:

- Formation of nonwoven nanofibrous scaffold

- Cells from the body are taken

- Cell expansion in culture

- Seed the cultured cells on nanofibrous scaffolds

- Leave in culture to form functional tissue

- Implant the scaffold in the injured part of the body.

- Thus tissue engineering involves scaffold formation, cell biopsy, culture, expanding of cells, seeding it on scaffold, and implantation.

\section{Nanofibers}

Nanofibers are defined as fibres with diameters less than 100 nanometers. In the textile industry, it is defined as the fibres as large as $1000 \mathrm{~nm}$ diameter.Fibres with diameter in nanometre range are called nanofibers. Many type of polymers are used in the production of nanofibers. Conventional spinning methods are used to produce nanofibers with very less diameter in nanometer range.

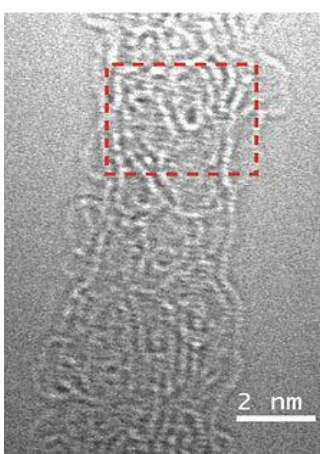

Figure 9: Nanofibers 


\section{International Journal of Science and Research (IJSR) \\ ISSN (Online): 2319-7064}

Index Copernicus Value (2013): 6.14 | Impact Factor (2014): 5.611

\section{Properties}

- Large specific surface area

- High porosity

- Small pore size

- Diameter range (50 - 1000) nm

\section{Nanofibrous Scaffolds}

Nanaofibrous scaffolds should generate new tissues which should possess the below properties:

- High porosity, adequate pore size

- High surface area.

- Biodegradability

- Biocompatibility

- Mechanical strength

Of all the other techniques to produce nanofibers, Electrospinning is the effective method, but in which we need a very high voltage. Whereas, Rotary jet spinning method (or) Centrifugal spinning method is a developing

method, in which controllable motor can control the entire machine and gives higher output when compared to other techniques.

\section{Methods of Preparing of Nanofibers}

Currently there are four major techniques available for the preparation of nanofibers: electrospinning, self-assembly, phase separation and template synthesis. Of these, electrospinning is the only one that can produce at large scale continuous nanofibers for industrial applications, while other techniques may generate more sophisticated structures and more versatile functionalities. Nanofibers synthesized by self-assembly and phase separation have had relatively limited studies that explored their application as scaffolds for drug delivery.

\section{Electrospinning Method}

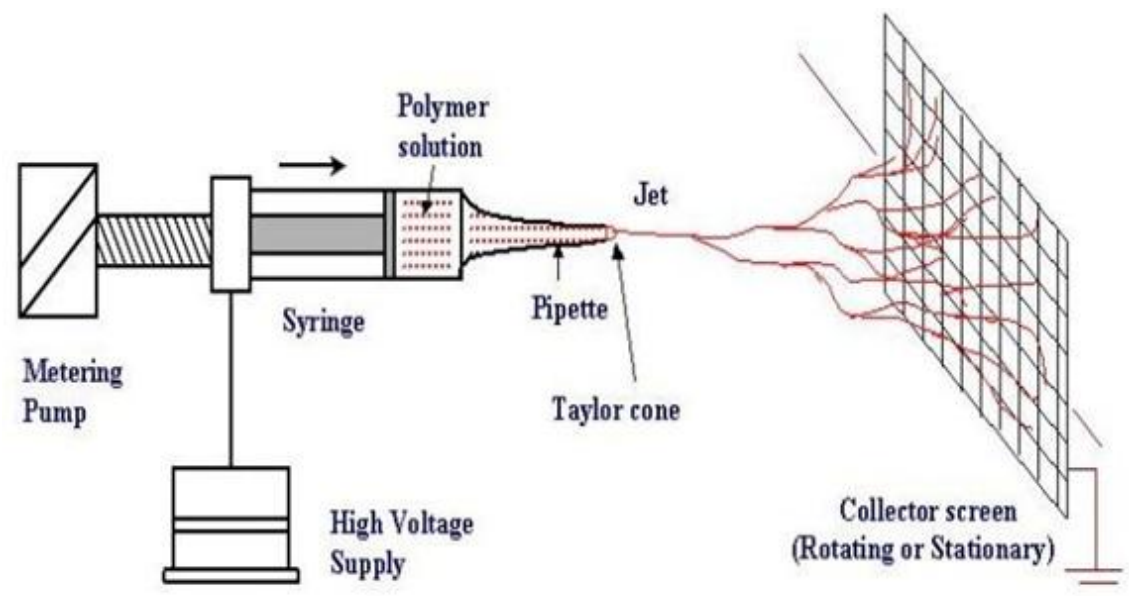

Figure 10: Electrospinning

In Electrospinning process, a very high voltage source is used. Polymer solution is injected into the syringe. One voltage source is placed into the solution and the other is connected to the collector. This creates an electrostatic force. As the voltage increases, the polymer from the tip of the needle ejects out and with increasing electrostatic force it makes the droplet to elongate and forms a conical shape which is known as Taylor cone and with increasing voltage, polymer from the tip of the Taylor cone ejects out as thin ribbon and get collected in the collector.

\section{Advantages of Electrospinning Method}

1) Control over porosity

2) Nanofibers with range $40 \mathrm{~nm}-2000 \mathrm{~nm}$ is possible

3) Suitable for tissue engineering and biomedical applications

\section{Disadvantages of Electrospinning Method}

1) Requires very high voltage source.

\section{Self-Assembly Method}

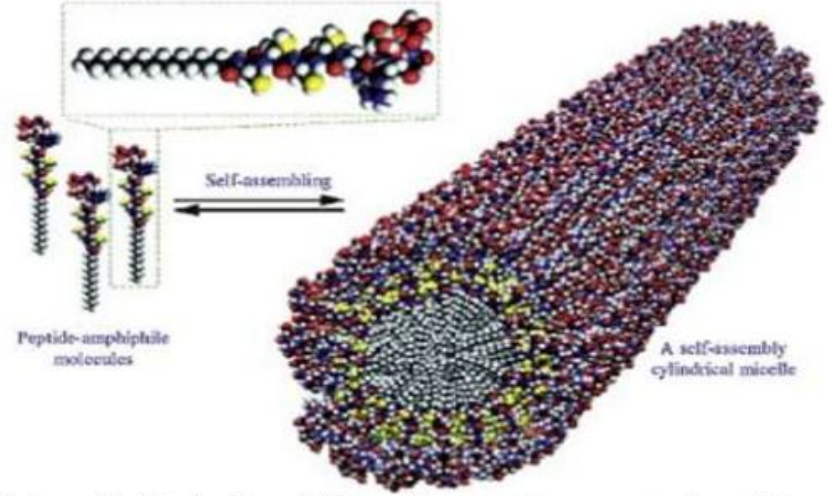

Schematic illustration of the self-assembly process of peptideamphiphiles functionalized to form a nanofiber $7.6 \pm 1 \mathrm{~nm}$ in diameter.

Figure 11: Self-Assembly Method

This is a bottom-up technique in which macroscale liquid is breakdown to form nanoscale fibers. The shape of nanofibers are based upon the building blocks where molecules arrange themselves to form nanofibers. Thus this technique this technique is used in forming scaffolds for drug delivery and tissue engineering. 


\section{International Journal of Science and Research (IJSR) \\ ISSN (Online): 2319-7064 \\ Index Copernicus Value (2013): 6.14 | Impact Factor (2014): 5.611}

Advantages of Self Assembly Method

1) No machinery required, orientation is random

\section{Disadvantages of Self Assembly Method}

1) Complex method

2) Fabrication is more complicated.

3) Limited to few polymers

\section{Phase Separation Method}

In this technique, polymer is introduced into the solution where polymer dissolution takes place, further taken to gelation, solvent extraction and freezing and drying and thus nanofibers are formed.

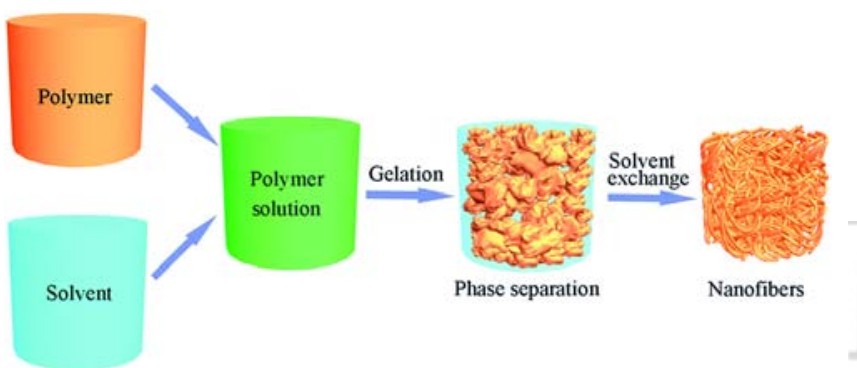

Figure 12: Phase Separation Method.

\section{Advantages of Phase Separation Method}

1) Simple method, does not require specialized equipment

2) Cheap method

3) Control over porosity

4) Diameters ranging from 50 to $500 \mathrm{~nm}$

\section{Disadvantages of Phase Separation Method}

1) This process is suitable for limited number of polymers.

2) Difficult for commercial setting.

\section{Template Method}

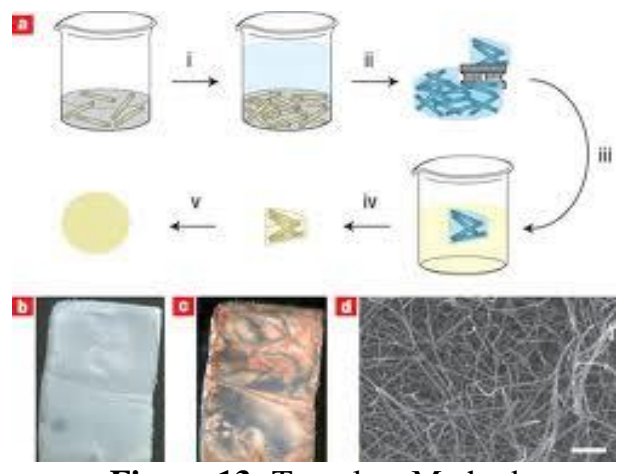

Figure 13: Template Method

In this method, nanostructured polymeric membrane is prepared to act as template, in which the targeting material is made to be in contact with the nanostructure to form nanofibers, and finally the template is removed to form independent nanofibers.

\section{Advantages of Template Method}

1) Low cost

2) Simple method

3) Highly controllable route to synthesizing and designing

\section{Disadvantages of Template Method}

1) Mass production is a challenge

2) Continuous long length of fibre is also a challenge

\section{Rotary Jet Spinning Method}

The developing method is Rotary jet spinning method or Centrifugal spinning method. This machine has a rotary reservoir. And hole(s) is/are made in it based on the output rate. It has a collector. The polymer solution is fed into the reservoir and controllable motor controls the machine. When the machine is $\mathrm{ON}$, with the help of motor reservoir starts to rotate and polymer ejects out from the reservoir through the hole as it rotates due to centrifugal force. The polymer ejecting out forms its own path and get collected in the collector. As soon as the polymer ejects out it get dried immediately when it comes into contact with the atmosphere. Thus thin silky ribbon like fibrous web is collected from the collector.
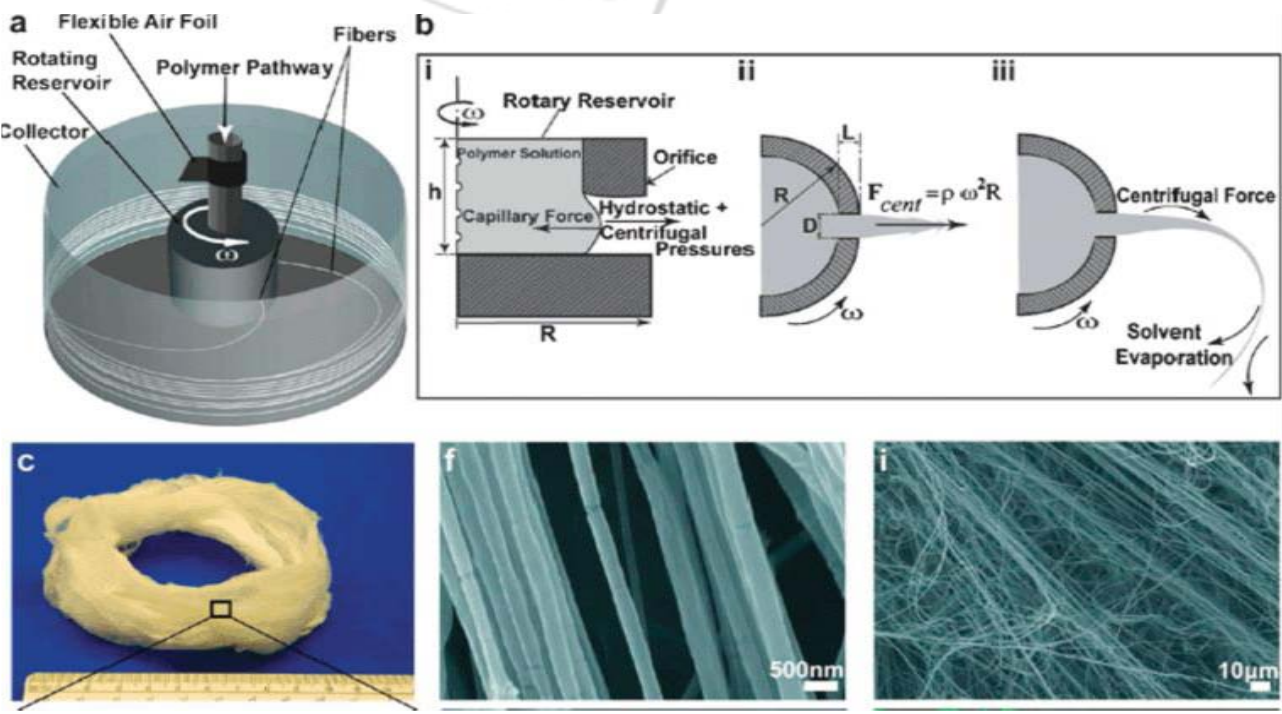

Figure 14: Rotary Jet Spinning Method

Volume 5 Issue 3, March 2016 


\section{International Journal of Science and Research (IJSR) \\ ISSN (Online): 2319-7064 \\ Index Copernicus Value (2013): 6.14 | Impact Factor (2014): 5.611}

\section{Advantages of Rotary Jet Spinning Method}

1) It gives a very high output when compared to the other methods.

2) It has a lot of control over fibre alignment and web porosity, hierarchical and spatial organization of fibrous scaffold and three-dimensional assemblies.

3) The end-result 3D structure shape can be set by varying how the fibres are collected. This technology is used to form tissue engineering scaffolds, or artificial organs upon which tissue can form and grow.

\section{Conclusion}

Development of nanofibers has created a great impact in tissue engineering. It can be produced by various techniques like Electrospinning, phase separation, self-assembly method etc. The most recent method of fine fibre production is Rotary jet spinning method or Centrifugal spinning method. It gives a very high output when compared to the other methods. When spun, the material stretches much like molten sugar does as it begins to dry into thin, silky ribbons.This system offers fabrication of naturally occurring and synthetic polymers. This technology is used to form tissue engineering scaffolds, or artificial organs upon which tissue can form and grow. The three dimensional synthetic biodegradable scaffolds produced with nanofibers by RJS technique acts excellently in cell binding, growth and differentiation. Thus the nanofibers production using RJS method is suitable for all kinds of tissue engineering such as skin, bone etc., which mimic the activities of the host one.

\section{References}

[1] Aezeden Mohamed, Malcolm (Mengqiu) Xing, (2012), „Nanomaterials and nanotechnology for skin tissue engineeringe, Int J Burn Trauma 2012; Vol.2, No.1, pp: 29-41

[2] U.Boudriot, R.Dersch, A.Greiner, J.H.Wendorff, „Tissue Engineering, drug delivery, wound healing via polymer nanofibers and nanotubes ${ }^{\text {ee }}$

[3] DhakshinamoorthySundaramurthi,

SwaminathanSethuraman, (2014), „Electrospun Nanofibers as Scaffolds for Skin Tissue Engineeringee, Article in Polymer Reviews.April 2014, Impact Factor: 6.16.DOI: $10.1080 / 15583724.2014 .881374$

[4] Haifeng Liu, Xili Ding, Gang Zhou, Ping Li, Xing Wei, and Yubo Fan, (2013), ,Electrospinning of Nanofibers for Tissue Engineering Applications ${ }^{\text {ee }}$, Journal of Nanomaterials, Volume 2013, Article ID 495708, 11 pages

[5] IlariaTocco, Barbara Zavan, Franco Bassetto, and Vincenzo Vindigni, (2012), „Nanotechnology-Based Therapies for Skin Wound Regeneration"e, Journal of Nanomaterials, Volume 2012, Article ID 714134, 11 pages, doi:10.1155/2012/714134

[6] Macarena Peran, Maria Angel Garcia, Elena LopezRuiz, Gema Jimenez and Juan Antonio Marchal, (2013), „How can Nanotechnology Help to Repair the Body? Advances in Cardiac, Skin, Bone, Cartilage and Nerve Tissue Regeneration", Materials 2013, Vol.6, pp.13331359

[7] Ming Chen, Melissa Przyborowski, and Francois Berthiaume, (2009), „Stem Cells for Skin Tissue
Engineering and Wound Healinge, Crit Rev Biomed Eng.2009, Vol.37, No.4-5, pp.399-421

[8] Muhammad Iqbal Sabir, Xiaoxue Xu, Li Li, (2009), J Master Sci(2009), Vol.44, pp.5713-5724

[9] Paula Mellado, Holly A.Mcllwee, Mohammad R,Badrossamay, Josue A.Goss, L.Mahadevan, and Kevin Kit Parker, (2011), „A simple model for nanofiber formation by rotary jet-spinningee, Applied Physics letter 99, 203107

[10] QuynhP.Pham, Upma Sharma, and AntoniosG.Mikos, (2006), ,Electrospinning of Polymeric Nanofibers for Tissue Engineering Applications: A Reviewe, Tissue Engineering, Volume 12, Number 5, 2006

[11] Rajesh Vasita, Dhirendra S katti, (2006), „Nanofibers and their applications in tissue engineeringe, International Journal of Nanomedicine 2006:I(I), pp.1530

[12] Richard A.F.Clark, Kaustabh Ghosh and Marcia G.Tonnesen, (2007), , Tissue Engineering for Cutaneous

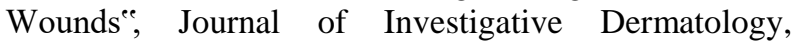
Vol.127

[13] Xiumei Mo, Dawei Li, Hany A.EI-Hamshary, Salem S.AI-Deyab, (2013), ,Electrospun nanofibers for Tissue Engineeringee, Journal of Fiber Bioengineering and Informatics Vol.6, No.3 (2013), pp.225-235

[14],,Tissue Engineeringe, Nature by technology, Vol.18, Supplement 2000 